\title{
Book Review: Mikkel Flyverbom's “The Digital Prism: Transparency and Managed Visibilities in a Datafied World"
}

\author{
Maximilian Heimstädt \\ Weizenbaum Institute \\ Hardenbergstraße 32 \\ 10623 Berlin
}

\section{Accepted for publication in Organization https://doi.org/10.1177/1350508420956318}

Some would argue that academic book reviews are an important form of transparency. In times when academic books are plentiful but expensive, reviews provide academics with objective assessments and help them make better purchasing decisions. However, anyone who has written a book review or whose work has been reviewed knows that the social practice of book reviewing is a much more multifaceted activity (see Chong, 2020). While it does involve rendering visible and intelligible some parts of a book, it also involves omitting others and sometimes even cloaking one's true opinion about a text.

While transparency has always played a role in many social activities (such as book reviewing), it has turned into one of the most dominant matters of concern in times of digitalization and datafication. In his new book, Mikkel Flyverbom draws together the growing body of research on transparency in a datafied world and translates it into an intuitive yet powerful framework for future work on this issue. Analogue to the introductory example of book reviews, Flyverbom argues that studying transparency as a mere matter of information transfer misses many (and the most interesting) of its social consequences. As an alternative to such an information-centered approach, he proposes visibility management as a 
communication-centered perspective, which refracts phenomena of digital transparency into networked practices of revealing and concealing.

The argument of the book unfolds over the course of five chapters. In the first chapter, Flyverbom engages with the way we think and speak about the technical environment we currently live in. Rather than drawing on terminology that alludes to a utopian detached reality ('cyberspace'), he argues that we should conceive of this environment as a 'digital backbone' (p. 56)1. Thinking of the digital in terms of material infrastructure acknowledges the highly consequential ways in which it is entangled in economic, social and political processes. It also opens new lines of inquiry into the everyday practices of visibility that take place in and around this infrastructure. The focal role these digital backbones play in our everyday lives has inevitably evoked discussions about their transparency and accountability.

In the second chapter, the author summarizes some of these discussions and problematizes the predominant 'information-focused approach' (p. 84) in transparency research. At its heart, such an approach sees good governance of people, organizations and society as problem of finding the right amount, quality and audience for disclosing information. Given the complex digital infrastructures and data practices, Flyverbom argues, this perspective can only inadequately capture what people actually do when they do transparency, i.e. the 'complex processes of meaning-making and interpretation' (p. 86). As a remedy to this shortcoming, transparency scholars should turn towards visibility as their core category and examine how digital infrastructures afford new forms of visibility management. While visibility management can be used as a lens for studying phenomena of transparency, it can also be used to analyze related phenomena such as rumors, leaks or secrecy.

In the second half of the book, the lens of visibility management is applied to different analytical levels. For each of the levels, Flyverbom demonstrates the type of insight that can be

1 Page numbers refer to the electronic version of the book. 
gained through his perspective vis-à-vis a purely informational approach. For these demonstrations he mostly draws on existing studies or media reports, but also incorporates his very personal experiences from spending some research time in Silicon Valley. Chapter three provides a broad overview of tensions between revealing and concealing, which individuals perceive when navigating digital infrastructures. The chapter covers issues such as the effects of anonymity and authenticity in online discourse, new digital practices of the self (e.g. fitness tracking, health monitoring), and the role of 'digital doubles' (p. 123) for processes of social evaluation (e.g. on the job market). Chapter four addresses the ambiguities of transparency as a company value and element of an organizational culture. For example, the chapter examines the case of the Silicon Valley firm Buffer. Buffer successfully presented itself as a radically transparent and truthful organization, by making all emails sent by individual employees visible to all other employees as well. However, as Flyverbom reports, this radical transparency only became possible because the firm still allowed employees to converse through non-transparent private messages (p. 157). Over time, more and more of the internal communication shifted to the semi-formal secrecy of private messaging (known to employees but less well-known to outside stakeholders) within a supposedly radically transparent organization. Chapter five eventually presents visibility management as an analytical lens that could also produce new insights on the role of transparency in political affairs and state governance. In times of populism and post-truth politics, many academics dream themselves back into times of more progressive and transparent political decision-making. It is therefore particularly interesting when Flyverbom reminds us that also past governments - oftentimes idealized as heralds of transparency - were not without their ambiguities. For example, although the Obama administration created unprecedented forms of transparency through its open government data initiatives, at the same time it held on to or even further reinforced certain institutional forms of secrecy around (digital) intelligence services. 
What this book sets out to do, and achieves, is to take stock of the lively yet heterogeneous field of (critical) transparency studies which has formed in recent years. Having played a focal role in the emergence of this field himself, Flyverbom manages not only to provide a comprehensive review of the relevant literature, but also to condense the field's findings into an intuitive and very versatile framework. The book does not match the breadth of empirical examples which we find in works such as Zuboff's (2019) The Age of Surveillance Capitalism. It also does not provide the genuinely perplexing details of comprehensive sociotechnical ethnographies (e.g., Ziewitz, 2019). However, through its accessible language and intuitive root metaphor (the prism) I believe that the book has the potential to substantially change how practitioners such as managers, policy-makers or journalists think about and act upon transparency. And finally, I also hope that the framework of this book can help the community of organizational scholars to become more reflexive about the role of digital transparency for its everyday work. This leads us back to the introductory example.

Why did $I$ decide to review this book? Because I felt entitled to create some more transparency in my niche of the academic book market? Because I wanted to do the author a favour? Or am I writing this review to become visible as a transparency expert on Twitter and add another preprint to my ResearchGate profile (hoping that it covers up the scarcity of 'toptier hits' on there)? What this brief example is supposed to show, and what remains one of the few blind spots in Flyverbom's analysis, is that the digital infrastructures and practices described by organization scholars have not stopped at their own doorstep. In fact, some scholars have already foreshadowed an 'Uberization of science' (Mirowski, 2019, p. 45) - a world in which researchers are completely dependent on the digital backbones of a few powerful technology companies running not journals, archives, review systems and data repositories. Although organization scholars recently launched a heated debate around the changing role of digital transparency in organizational research methods (Aguinis \& Solarino, 2019; Pratt et al., 2020) this debate is only the tip of the iceberg. To date, we know only little 
about how new digital infrastructures and practices of revealing and concealing change the process and outcome of academic knowledge production. Yet becoming more reflexive about these transformations is a prerequisite for truly critical organizational research. We should therefore ask ourselves: What does organizational research look like when viewed through the digital prism?

\section{References}

Aguinis, H., \& Solarino, A. M. (2019). Transparency and replicability in qualitative research: The case of interviews with elite informants. Strategic Management Journal, 40(8), $1291-1315$.

Chong, P. K. (2020). Inside the Critics' Circle. Princeton University Press.

Mirowski, P. (2019). Hell is truth seen too late. Boundary 2, 46(1), 1-53.

Pratt, M. G., Kaplan, S., \& Whittington, R. (2020). Editorial essay: The tumult over transparency: Decoupling transparency from replication in establishing trustworthy qualitative research. Administrative Science Quarterly, 65(1), 1-19.

Ziewitz, M. (2019). Rethinking gaming: The ethical work of optimization in web search engines. Social Studies of Science, 49(5), 707-731.

Zuboff, S. (2019). The Age of Surveillance Capitalism: The Fight for a Human Future at the New Frontier of Power. Profile Books. 